\title{
Adolescent perceptions of orthodontic treatment risks and risk information: A qualitative study
}

\author{
John Perry $^{\mathrm{a}, *}$, Ilona Johnson ${ }^{\mathrm{a}}$, Hashmat Popat ${ }^{\mathrm{a}}$, Maria Z. Morgan ${ }^{\mathrm{a}}$, Paul Gill ${ }^{\mathrm{b}}$ \\ ${ }^{\text {a }}$ Cardiff University School of Dentistry, Heath Park, Cardiff, CF14 4XY, UK \\ ${ }^{\mathrm{b}}$ School of Healthcare Sciences, Cardiff University, Cardiff, CF10 3AT, UK
}

\section{A R T I C L E I N F O}

\section{Keywords:}

Orthodontics

Risk

Communication

Qualitative research

Focus groups

Decision making

\begin{abstract}
A B S T R A C T
Introduction: For effective risk communication, clinicians must understand patients' values and beliefs in relation to the risks of treatment. This qualitative study aimed to explore adolescent perceptions of orthodontic treatment risks and risk information.

Methods: Five focus groups were carried out with 32 school/college pupils aged 12-18 in Wales, UK. Participants were purposively selected and had all experienced orthodontic treatment. A thematic approach was used for analysis and data collection was completed at the point of data saturation.

Results: Four themes emerged from the data; (a) day-to-day risks of orthodontic treatment, (b) important orthodontic risk information, (c) engaging with orthodontic risk information and (d) managing the risks of orthodontic treatment. Day-to-day risks of orthodontic treatment that were affecting participants "here and now" were of most concern. Information about preventing the risks of treatment was deemed to be important. Participants did not actively seek risk information but engaged passively with information from convenient sources. Perceptions of risk susceptibility influenced participants' management of the risks of orthodontic treatment.

Conclusions: This study demonstrates that adolescent patients can understand information about the nature and severity of orthodontic treatment risks. However, adolescent patients can have false perceptions if the risks are unfamiliar, perceived only to have a future impact or if seen as easy to control. Adolescent patients must be provided with timely and easily accessible risk information and with practical solutions to prevent the risks of treatment.

Clinical significance: The views and experiences gathered in this study can assist clinicians to better understand their young patients' beliefs about treatment risks, facilitate effective risk communication and contribute to improved patient-centred care.
\end{abstract}

\section{Introduction}

In healthcare settings, the concept of risk, has been described as a possibility of loss, injury, disease, or death [1]. A patient cannot make genuinely informed choices about their care without understanding the risks involved [2]. Risk communication is a collaborative process, whereby decisions about treatment are made through the open exchange of information and opinion about risk between two or more parties [3]. Effective communication of risk is a requisite for shared decision-making and the provision of person-centred care $[4,5]$.

The risks of orthodontic treatment have been defined broadly as any of the deleterious or iatrogenic effects of orthodontic treatment, or any potential adverse outcomes or consequences [6-8]. Like many dental procedures, orthodontic treatment is often elective and takes place over an extended period, requiring considerable investments of time and resources. Although some orthodontic patients commence treatment at a stage when they are not legally competent to consent [9], studies have shown that adolescent patients can understand risk information and participate meaningfully in treatment decisions $[10,11]$. In addition, adolescent orthodontic patients are normally responsible for their own oral hygiene and care of their appliances at home. For treatment success, the risks of orthodontic treatment must therefore be carefully articulated to adolescent patients.

Landmark court rulings in the United Kingdom [12], United States [13], Canada [14] and Australia [15] have shifted the way in which healthcare risks are communicated. When communicating risk, clinicians must now understand their patients' individual values, beliefs in relation to the risks of treatment and their risk information needs. However, the

\footnotetext{
* Corresponding author at: Ilam Orthodontics 3 Clyde Road, Ilam, Christchurch, 8041, New Zealand.

E-mail addresses: john@iortho.co.nz (J. Perry), johnsonig@cardiff.ac.uk (I. Johnson), hash@bracesnfaces.com.au (H. Popat), morganmz@cardiff.ac.uk (M.Z. Morgan), gillp3@cardiff.ac.uk (P. Gill).
} 
development of orthodontic risk communication tools, such as information leaflets [16-18], audio-visual information packages [19], decision aids $[20,21]$ and messaging apps $[22,23]$, have rarely been guided by the views of adolescent patients who may have different perceptions of risk information to professionals [24] and primary carers [11].

Qualitative studies suggest that adolescent orthodontic patients can experience many risks of treatment including pain and dietary impacts, dental aesthetic issues, problems with oral hygiene, appliances breaking and issues with retainers [20,25-29]. In addition, adolescent orthodontic patients appear to be concerned about demineralisation, gingival irritation, relapse and root shortening [20,30,31]. However, adolescent perceptions of orthodontic treatment risks have rarely been explored in detail and little is known about how patients' risk perceptions might change during treatment.

The literature suggests orthodontic patients have a desire for wide ranging information about the risks of treatment, including effects on diet and speech, treatment duration and procedures, preventative advice and the implications of retainers $[16,20,25,32]$. These studies however, have not identified the risk information that orthodontic patients most need or use when making choices about treatment and little is known about how young orthodontic patients perceive information about the risks involved in their care. As such, this study aims to understand adolescent perceptions of orthodontic treatment risks and risk information.

\section{Materials and methods}

Ethical approval was granted by Cardiff University Dental School Research Ethics Committee (Ref 1527).

\subsection{Recruitment process}

Participants were English speaking, secondary school/sixth form college pupils, 12-18 years of age, of mixed gender and ethnicity. Purposive sampling was used to select a range of year groups and schools/colleges in different geographical and socio-economic areas of Cardiff. To ensure meaningful insights, the sampling strategy was designed to include diverse perspectives and pupils with a range of orthodontic treatment experiences. This included pupils who had discussed treatment with a dentist/orthodontist but had not proceeded, pupils who were undergoing treatment at the time of the study and pupils who had completed treatment and were in different points of retention. Data collection and sampling were conducted in parallel and the preliminary findings informed participant selection. Recruitment continued until data saturation was achieved; this was the point at which no new themes or ideas were emerging [33].

\subsection{Conduct of focus groups}

Focus groups were conducted at participants' schools/colleges between January and April 2016. Each focus group was conducted with pupils who belonged to the same year group to facilitate naturalistic discussions. The moderator (JP) was a male, white Caucasian clinician (postgraduate trainee in orthodontics) who had completed focus groups methods training over a six-month period with experienced researchers (IJ and PG). JP kept a reflective journal to help recognise the influence of personal biases and assumptions throughout the study. The assistant moderator (IJ) was a female, white Caucasian clinician, experienced in focus group studies.

The research team designed a questioning route informed by the existing risk communication literature and guidance on focus groups [34,35] (Appendix A). The questioning route was used consistently across groups and involved a number of approaches to explore participants' perceptions of orthodontic treatment risks and risk information; the first involved open questions, the second involved asking participants to write down ideas on sticky notes and the third involved a sorting exercise, using picture/word cards of orthodontic treatment risks identified by orthodontists as important risks during a Delphi exercise [36] (Appendix B). Additional questions were asked in a flexible manner to explore emerging issues raised by participants.

Focus groups lasted 45-60 min and were digitally audio recorded. The assistant moderator took field notes including a record of contextual details and non-verbal communication. Participants were blinded to the professional expertise of the moderators.

Audio recordings were transcribed verbatim, by one author (JP) and imported into NVivo (version 10, QSR International, Victoria, Australia) to assist with data management. Transcripts were anonymised using pupil codes instead of names and were analysed in a timely fashion to inform future data collection.

\subsection{Data analysis}

All data were reviewed and coded by JP and all coding was verified by IJ. Textual data and coding were discussed as a group to enrich interpretation. Themes were derived from the data using a thematic analysis approach [37]. Initially, each transcript was read to enable familiarity with the data and coding notes were recorded detailing thoughts, observations and early interpretations. Emergent themes were then developed by clustering related initial broad-based codes and searching for connections across them and finally, data were categorised and themes defined to capture their essence. Data contradicting emerging concepts and ideas were searched for and discussed to increase the depth of the analysis.

To encourage participant validation, pupils were given the opportunity to feedback on results; verbally during group debriefs and shortly after data analysis via feedback forms. Any feedback from the respondents was recorded and used to refine theme and theory development.

\section{Results}

A total of five focus groups were conducted at five different schools/ colleges, with 32 participants (Table 1). The gender ratio of participants was equal.

Four interconnected themes emerged from the data; (a) day-to-day risks of orthodontic treatment, (b) important orthodontic risk information, (c) engaging with orthodontic risk information and (d) managing the risks of orthodontic treatment. These four themes arose across all focus groups.

\subsection{Day-to-day risks of orthodontic treatment}

Participants told stories about the risks of living with a brace and dayto-day problems. Issues such as pain, difficulty eating, "braces breaking", "cuts" and "ulcers" were an expected part of the orthodontic treatment process. Participants expected these issues due to previous experiences or information received from family, friends or dental professionals. However, issues such as pain and difficulty eating were still described as having a significant and emotional impact on participants' lives.

Pupil 45F: "I actually cried because I couldn't eat (group members laugh). I was sitting on my bed and I was crying (laughs). They were hurting and I couldn't eat, I was really hungry."

Participants described their resilience in dealing with everyday risks and many elected to "put up" with these day-to-day issues. The benefits of treatment were strong motivators for tolerating the negative aspects of orthodontic treatment and complying with healthcare recommendations. For example, participants tolerated problems with wearing retainers so that their "new smile" would be maintained.

\subsection{Important orthodontic risk information}

Participants were familiar with common risks such as pain, ulceration or appliances breaking but knew less about specific clinical risks such as root resorption and demineralisation. However, the sticky notes and visual aids used during the sorting exercise helped participants to 
Table 1

Participant demographics.

\begin{tabular}{|c|c|c|c|c|}
\hline Focus group number & School year group (age in years) & Pupil code ${ }^{\mathrm{a}}$ & Ethnicity & Experience of orthodontics \\
\hline 1 & $8(12-13)$ & $\begin{array}{l}11 \mathrm{~F} \\
12 \mathrm{~F} \\
13 \mathrm{M} \\
14 \mathrm{M} \\
15 \mathrm{M}\end{array}$ & $\begin{array}{l}\text { White Caucasian } \\
\text { Black African/Caribbean } \\
\text { White Caucasian } \\
\text { White Caucasian } \\
\text { White Caucasian }\end{array}$ & $\begin{array}{l}\text { Completed treatment } \\
\text { Undergoing treatment } \\
\text { Undergoing treatment } \\
\text { Undergoing treatment } \\
\text { Undergoing treatment }\end{array}$ \\
\hline 2 & $10(14-15)$ & $\begin{array}{l}21 \mathrm{~F} \\
22 \mathrm{M} \\
23 \mathrm{M} \\
24 \mathrm{M} \\
25 \mathrm{M}\end{array}$ & $\begin{array}{l}\text { White Caucasian } \\
\text { Black African/Caribbean } \\
\text { White Caucasian } \\
\text { White Caucasian } \\
\text { White Caucasian }\end{array}$ & $\begin{array}{l}\text { Completed treatment } \\
\text { Completed treatment } \\
\text { Completed treatment } \\
\text { Completed treatment } \\
\text { Undergoing treatment }\end{array}$ \\
\hline 3 & $10(14-15)$ & $\begin{array}{l}31 \mathrm{~F} \\
32 \mathrm{~F} \\
33 \mathrm{~F} \\
34 \mathrm{~F} \\
35 \mathrm{M} \\
36 \mathrm{M} \\
37 \mathrm{M}\end{array}$ & $\begin{array}{l}\text { Black African/Caribbean } \\
\text { Black African/Caribbean } \\
\text { Black African/Caribbean } \\
\text { Black African/Caribbean } \\
\text { Arab } \\
\text { Black African/Caribbean } \\
\text { Asian }\end{array}$ & $\begin{array}{l}\text { Undergoing treatment } \\
\text { Undergoing treatment } \\
\text { Undergoing treatment } \\
\text { Undergoing treatment } \\
\text { Undergoing treatment } \\
\text { Undergoing treatment } \\
\text { Undergoing treatment }\end{array}$ \\
\hline 4 & $11(15-16)$ & $\begin{array}{l}41 \mathrm{~F} \\
42 \mathrm{~F} \\
43 \mathrm{~F} \\
44 \mathrm{~F} \\
45 \mathrm{~F} \\
46 \mathrm{M} \\
47 \mathrm{M}\end{array}$ & $\begin{array}{l}\text { White Caucasian } \\
\text { White Caucasian } \\
\text { Black African/Caribbean } \\
\text { White Caucasian } \\
\text { Black African/Caribbean } \\
\text { White Caucasian } \\
\text { White Caucasian }\end{array}$ & $\begin{array}{l}\text { Undergoing treatment } \\
\text { Undergoing treatment } \\
\text { Completed treatment } \\
\text { Completed treatment } \\
\text { Completed treatment } \\
\text { Completed treatment } \\
\text { Undergoing treatment }\end{array}$ \\
\hline 5 & $13(17-18)$ & $\begin{array}{l}51 \mathrm{~F} \\
52 \mathrm{~F} \\
53 \mathrm{~F} \\
54 \mathrm{M} \\
55 \mathrm{M} \\
56 \mathrm{M} \\
57 \mathrm{M} \\
58 \mathrm{M}\end{array}$ & $\begin{array}{l}\text { White Caucasian } \\
\text { White Caucasian } \\
\text { White Caucasian } \\
\text { White Caucasian } \\
\text { White Caucasian } \\
\text { White Caucasian } \\
\text { White Caucasian } \\
\text { White Caucasian }\end{array}$ & $\begin{array}{l}\text { Completed treatment } \\
\text { Completed treatment } \\
\text { Completed treatment } \\
\text { Did not proceed with treatment } \\
\text { Did not proceed with treatment } \\
\text { Did not proceed with treatment } \\
\text { Completed treatment } \\
\text { Undergoing treatment }\end{array}$ \\
\hline
\end{tabular}

${ }^{\mathrm{a}} 1$ st digit $=$ focus group number, 2 nd digit $=$ pupil number, $\mathrm{F}=$ female, $\mathrm{M}=$ male.

understand these more complex issues and once understood, participants described these risks as being important (Table 2). One participant spoke about the potential consequences of root resorption.

Pupil 23M: "That is important [to know about root resorption]. You shouldn't be losing teeth. Your tooth [root] dissolves and then you don't have a tooth do you? You don't want a fake one [a fake tooth], you want a proper one."

Participants also described the visual aids as important for managing their expectations of the risks of treatment and for improving motivation and compliance.

Pupil 51F: "It sort of scares you don't it, if you don't clean your teeth like that [the picture of demineralisation] ... So then you look after your teeth because you know what to expect if you don't look after your teeth."

The group discussions and exercises indicated that participants had a desire not only to know what risks were involved in their treatment but also how the risks might be prevented. Participants provided advice and self-help tips for common risks, as illustrated by this conversation about braces rubbing and causing ulcers.

Pupil 21F: (Talking to Pupil 25M who was undergoing treatment) "I'd just make sure you use the wax and you won't get all the cuts."

Pupil 23M: "Ah yea, they make you put it on the back [of the brace], so it stops the rubbing."

Pupil 24M: "Painkillers and ulcer cream."

Pupil 21F: "I'd stock up on the Bonjela."

Participants were most concerned with day-to-day risks that were affecting them "here and now". For example, participants who had just started treatment highlighted the importance of information about how an orthodontic appliance might feel and the early physical and social impacts. Participants' focus on their current circumstances revealed that future issues were rarely considered. For example, participants in the early stages of treatment had not yet considered the challenges associated with wearing retainers. Due to this lack of future planning, participants also saw regular prompts, reminders and encouragement about previous risk messages as invaluable.

Pupil 46M: "I sort of had a kick up the backside [from the orthodontist] and then I started wearing them [retainers] ... I was lucky I started wearing them because if I didn't start wearing them when I did my teeth would have gone back to the way they were."

\subsection{Engaging with orthodontic risk information}

Participants talked about their engagement with risk information when making decisions about orthodontic treatment. Risk information had been received out of convenience, for example, when family or friends had spoken to participants or when dental professionals had given advice. In addition, participants happened to come across orthodontic risk information when watching television programmes and when spending time on the internet or with social media. Participants did not speak of actively seeking risk information.

Risk messages were considered helpful for decision-making when received from a trusted and reliable source, such as a parent or dental professional. For example, one participant talked about how his mother had given him a good awareness of the discomfort associated with orthodontic treatment.

Pupil 35M: "My mum had a brace ... she was like you'll have pain the 
Table 2

Important orthodontic treatment risks discussed during the focus groups.

\begin{tabular}{|c|c|c|}
\hline Risk & $\begin{array}{l}\text { Number of focus groups in which risk discussed } \\
\text { (total focus groups }=5 \text { ) }\end{array}$ & Important information about risk from an adolescent perspective $\mathrm{a}^{\mathrm{a}}$ \\
\hline Appliances breaking & 5 & $\begin{array}{l}\text { - "try not to bang your teeth so you don't break the brace" } \\
\text { - "braces are easy to break" }\end{array}$ \\
\hline Consequences of no treatment & 3 & $\begin{array}{l}\text { - "... if you refuse to have braces, you're not going to get any better, if they [the teeth] are } \\
\text { terrible then obviously you want them better" }\end{array}$ \\
\hline Cuts and ulcers & 5 & $\begin{array}{l}\text { - "the wires are sharp, how to manage this + using wax" } \\
\text { - "braces rub and stab your cheeks, get a gel to stop ulcers" }\end{array}$ \\
\hline Demineralisation & 5 & - "if you don't brush your brace properly, your teeth will go all minging" \\
\hline Gingivitis & 5 & - "you've got to keep brushing or your gums will get damaged" \\
\hline Pain/discomfort & 5 & $\begin{array}{l}\text { - "braces hurt for a few days" } \\
\text { - "pain and painkillers i.e. dealing with it" } \\
\text { - "braces feel weird for a few hours after they are put in" }\end{array}$ \\
\hline Problems eating & 5 & $\begin{array}{l}\text { - "you may not be able to eat for the first few days" } \\
\text { - "what to eat or not eat, chew carefully" } \\
\text { - "foods and drinks to avoid" } \\
\text { - "don't eat anything too crunchy or sweet" } \\
\text { - "don't eat really crunchy stuff" }\end{array}$ \\
\hline Problems speaking & 2 & - "you won't be able to speak probably at the start but you will get used to it" \\
\hline Relapse & 5 & $\begin{array}{l}\text { - adolescents may not consider retainers until the time comes so "expect retainers" } \\
\text { - retainers may feel "too big" or "really tight", "really painful" and "like they are squeezing } \\
\text { your teeth" but they are worth the effort }\end{array}$ \\
\hline Root resorption & 5 & $\begin{array}{l}\text { - "You need strong [tooth] roots." } \\
\text { - "You don't want a fake one [a fake tooth], you want a proper one." }\end{array}$ \\
\hline
\end{tabular}

${ }^{\text {a }}$ Representative sticky note comments and quotations from focus group participants describing important information about risk.

first couple of weeks, then it'll be fine, then it's gonna be worth it in the end and I was like OK."

However, for others, risk information relayed from sources close to them had been unreliable and caused worry and distress. This was often because family and friends had conveyed the risk messages in a way that magnified their own concerns, leading to questions about whether to proceed with treatment.

Pupil 46M: "My brother had braces and he was like, 'when you having your braces done?' He knew I was having 'em soon and he was like, "you won't be able to eat". He basically wound me up for like the whole time [before having a brace]. So I sat in the waiting room [at the orthodontist's] and I was thinking of what he was saying and I was like, do I really have to have them?"

Participants talked about weighing up information about the risks and benefits of orthodontic treatment. Participants expected that treatment would involve a certain level of hardship but those who had decided to proceed with orthodontic treatment, spoke about doing so because they perceived the potential benefits of treatment to outweigh whatever risks were involved and so were willing to "deal with" the risks of orthodontic treatment.

Pupil 51F: “...it just happens doesn't it [cuts and ulcers]. It's like if you want a smile, like nice teeth at the end you just kind of put up with it."

JP: "How did you feel when you found out that you would need teeth out [extracted]?"

Pupil 47M: "I didn't really mind."

Pupil 41F: "I was relieved, anything to get my teeth straight. I don't care."

JP: “Was it [orthodontic treatment] still worth it?"

Pupil 41F: "Yea, definitely... it's totally worth it."

Pupil 46M: "It is totally worth it."
Decisions not to proceed with treatment were influenced by participants' perceived lack of treatment need and acceptance of dental appearance and self. Risks associated with orthodontic care had little influence on their decisions to avoid treatment.

Pupil 55M: "So I could have had 'em [braces], but it's just the fact that I was alright with how my teeth looked, otherwise I would have had 'em. It wasn't like the pain or anything of having them on, like plenty of our friends had braces on."

\subsection{Managing the risks of orthodontic treatment}

A number of participants perceived themselves to be responsible for managing the risks of orthodontic treatment. These individuals expressed a sense of ownership over their appliances and oral health and described the importance of daily oral hygiene practices to prevent the risks of treatment.

Pupil 24M: "You have to brush your teeth every day."

Pupil 23M: "Yes, if you don't brush them properly, your teeth will go all minging."

Some participants reported increased compliance with heath recommendations after they had experienced risks such as caries, appliances breaking and relapse. For these participants, the sense of responsibility, reality and fear induced by their risk experiences appeared to have a greater effect on their health behaviour than any advice given to them in the past. In contrast, other participants described how they pushed the boundaries and took risks with their oral health. For example, one participant talked about trying to manage the risks of his sugary diet with frequent toothbrushing.

Pupil 47M: "I brush my teeth up to three times a day but I have a lot of sugar. I got a can of coke in my pocket right now, so I have a lot of sugar (group members laugh)."

Another participant spoke of how they had decided to ignore their 
orthodontists' dietary advice after trying a sweetened beverage and suffering no obvious or immediate ill effects.

\section{Discussion}

This qualitative study used focus groups to provide a naturalistic setting in which to elicit adolescents' collective views about the risks of orthodontic treatment. A thematic qualitative approach to analysis provided rich and detailed information to explain the emotions, decisions and behaviours of the respondents.

This study has shown that adolescent patients can understand information about the nature and severity of the day-to-day risks of orthodontic treatment, such as appliances breaking, cuts and ulcers, gingivitis, pain and problems eating and speaking. Furthermore, with appropriate support adolescent patients can grasp complex orthodontic issues, such as the consequences of no treatment, demineralisation, relapse and root resorption and become aware of their impact on health and quality of life.

Participants in this study did not actively seek risk information but were passive receivers of information from sources that were trusted, easily accessible and convenient. This finding is supported by theories in the decision-making sciences that suggest patients take shortcuts when making decisions and simplify healthcare choices by relying only on the information that is readily available to them [38]. However, as the present study shows, risk information received by patients is not always reliable or helpful for decision-making. The onus is therefore on clinicians to provide patients with accurate information that it easy to access and understand. The simple visual aids used in this study appeared to help participants understand the risks of orthodontic treatment. Previous research also supports the use of multimedia as a risk communication tool $[12,13,17-19]$. The present study also provides valuable data about how the risks of orthodontic treatment may be communicated in lay terms in a way that is relevant to patients $[16,20]$. This evidence can be used to guide the development of innovative risk communication tools and patient resources.

The participants' perceptions of orthodontic treatment risks appeared to be closely related to their understanding of treatment benefits. The problems and hardships associated with treatment were tolerated and accepted by participants to secure the perceived benefits of treatment. Positive treatment outcomes, such as improved appearance and confidence, motivated participants to proceed with treatment and comply with health recommendations. Risks were something to be managed but were rarely a barrier to the acceptance of care. These findings resonate with previous research $[32,39,40]$ that suggests the benefits of orthodontic treatment are highly valued. Furthermore, evidence from the wider literature has reported adolescents engage in activities when they perceive the benefits of participation to outweigh the risks involved [41]. Careful communication of the risks and benefits of treatment is therefore needed to manage patient expectations. In addition, emphasising the benefits of behaviour change, rather than the harms of not changing behaviour, may be an effective approach to communicating risk to patients [42].

In this study, differences existed between some adolescents' perceptions of and their actual susceptibility to the risks of orthodontic treatment. Reported unhealthy behaviours were related to risks that were unfamiliar to participants. For example, one participant ignored their orthodontist's diet advice after suffering no obvious or immediate demineralisation following a sweetened beverage. In addition, when participants recognised that an adverse event had clearly occurred, their compliance with health advice increased dramatically. These findings support evidence from the medical literature that suggests risks are perceived as more likely to occur if they are familiar and easily brought to mind [43]. A sense of control also appeared to influence the adolescents' attitudes towards the risks of treatment [41]. For example, one adolescent felt he could self-manage the risks of a high sugar diet through frequent toothbrushing. To manage these unrealistic risk perceptions it is important that orthodontic patients are empowered with sufficient information about the risks of treatment for informed decision-making.
The perceived immediacy of the risk also appeared to influence adolescents' perceptions and health behaviour. For example, sugary drinks were consumed by participants as they were not seen to have immediate harmful consequences. In addition, participants most desired treatment information pertaining to their immediate circumstances and future issues were rarely considered. Subsequently, the adolescents' information needs were dynamic and changed over the course of treatment. Previous research from the wider medical literature suggests that risks with immediate effects are perceived to be more likely $[44,45]$ and that future orientation may not be established until post-adolescence [46]. Orthodontists should be aware that risk information pertinent to patients' current orthodontic circumstances will be best received $[13,16]$ and advice about future issues may be forgotten or not fully considered $[15,47,48]$. The timing of information provision should be carefully considered and risk messages may need to be reinforced throughout treatment. This practice would support risk communication as a process rather than a one-off event [3] and takes into account young orthodontic patients' ability to develop better decision-making skills over time [49].

The data suggest many adolescent orthodontic patients want to manage the risks of treatment themselves and this evidence supports the need for patient-centred care and shared decision-making in orthodontic practice [50,51]. Participants described risks in the context of how they could be prevented or managed. Practical risk prevention strategies, such as diet advice, appliance care and oral hygiene instruction given alongside specific risk details are likely to be helpful for patients and increase their feelings of ownership of their treatment.

While focus group data can be influenced by social acceptability bias [52], all participants in each focus group were successfully encouraged to contribute to the data, two moderators were used for effective participant management and the same themes emerged across the focus groups regardless of group dynamics. In addition, to encourage candid responses, participants were blinded to the professional expertise of the moderators [53]. Given the size and nature of the sample group, the findings cannot be assumed to be representative of all patients seeking or undergoing orthodontic treatment. However, consistent themes were demonstrated across a broad sample of participants and the findings may be transferable to other similar settings.

An extensive insight into adolescents' views about orthodontic treatment risks and their attitudes towards risk information has been provided. This evidence can support the development of orthodontic risk communication tools and assist other dental and medical specialties that communicate risk with young people.

\section{Conclusions}

This study has shown that adolescent patients can understand the nature and severity of many of the risks of orthodontic treatment. However, adolescent orthodontic patients can have false perceptions if the risks of treatment are unfamiliar, perceived only to have a future impact or if seen as easy to control. Risk information appears to be more easily communicated if it relates to an adolescent patients' immediate orthodontic situation. Therefore, clinicians should carefully consider their timing of information provision and prepare to reinforce risk messages during treatment. To communicate risk effectively, adolescent patients must be provided with reliable and easily accessible information about the effects of adverse orthodontic outcomes and with practical solutions to prevent the risks of treatment.

\section{Acknowledgements}

This work was funded by a Faculty of Dental Surgery Small Research Grant 2016 awarded by the Royal College of Surgeons of England. The authors thank the school staff and pupils in the City of Cardiff area who have supported this research. 
Appendix A. . Questioning route

\begin{tabular}{|l|l|}
\hline Time: & Name of school/college: \\
\hline Table map, names and characteristics of interest: \\
\hline Notes: \\
\\
\end{tabular}

- Introduction of moderators

- Ground rules - phones on silent, aim of interview, recording details, listening to each other and talking one at a time, no right or wrong answers, can ask for more information, privacy, confidentiality, name tags.

So we're going to be talking about wearing braces and we want to know what year <year group > pupils think about wearing braces. This is a really great chance for you to help teenagers in the future who are about to wear braces. At the end of the group interview there'll be the opportunity to talk with the tape recorder switched off.

You don't have to respond all the time or take part in the whole interview and you can leave at any time, although obviously we'd like to hear what you have to say!

This group chat will take about 45 minutes. Does anyone have any questions?

\section{SWITCH RECORDER ON}

The first thing I need you to do is to say your name and your favourite hobby. We'll go round to the left and I'll start...

Main questions:

1) So we're talking about dental braces and I'm interested to know what you've seen. Can you describe the kinds of dental braces that you've seen on other people or worn yourself?

2) So, how did you feel about wearing a brace?

3) So what were you told about braces?

4) We would like you to help design an information pack for teenagers who are thinking about wearing braces. Imagine you are just about to wear a brace. What would you like to know?

Get participants to write down examples on sticky notes and put in middle of the circle.

5) These are things that orthodontists think people should be told about braces (rating exercise)

Get participants to rank in order of importance. As people rank, probe, explore.

\section{Debriefing:}

- Is there anything else you'd like to discuss that we haven't covered?

- Summary of main points. Do you think this summary covers what we just talked about?

- Address any harmful comments.

- Many people do not have any problems wearing braces but if you are worried about anything to do with wearing braces then please say now or you're very welcome to talk to us, your teacher or your dentist afterwards.

\section{- SWITCH OFF RECORDER}

- You can now say anything about wearing braces which you may not have wanted to say when the tape recorder was on.

- A summary of the topics we talked about in this group interview will be given to you in about a month. You will be able to give us feedback about the summary to say if you agree or disagree with anything.

- Thanks for all your help today, that was really excellent and it will help teenagers who are thinking about having braces in the future. 
Appendix B. . Picture/word cards of orthodontic treatment risks used in the sorting exercise
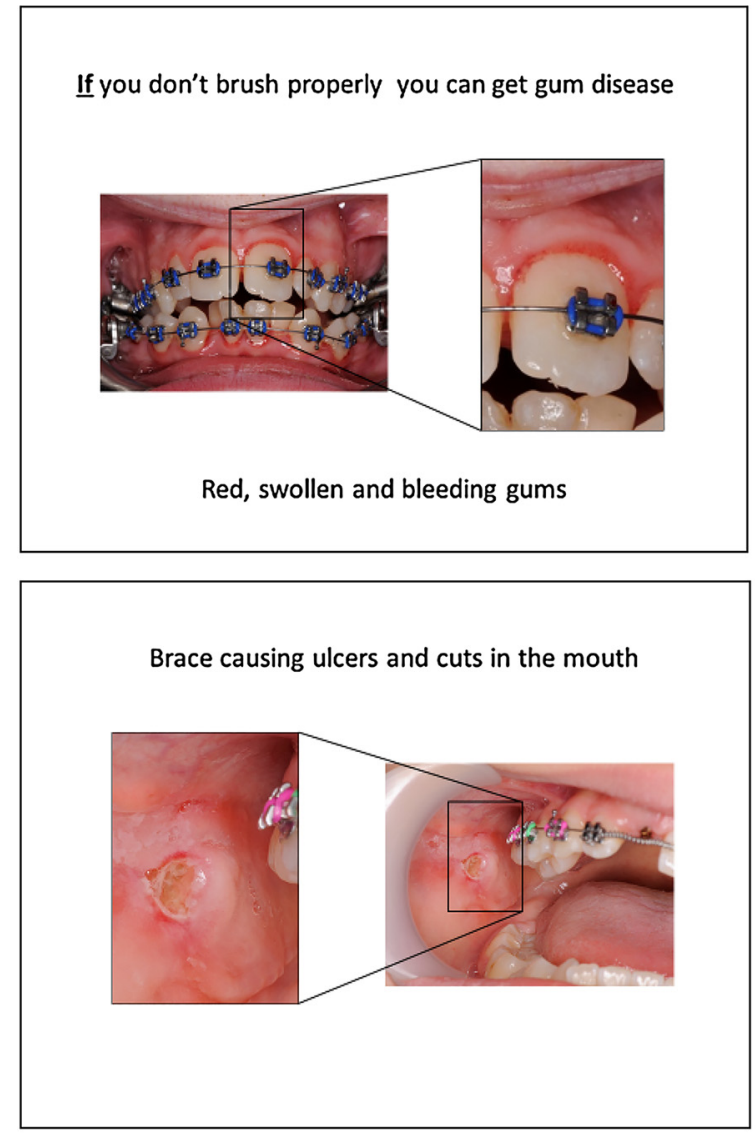

If you don't brush properly or have lots of sugar you can get stains on the teeth after the braces are taken off

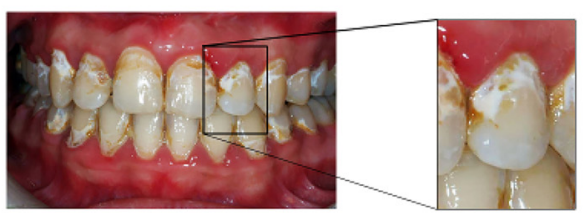

This is caused by early tooth decay and if really bad can cause holes in the teeth

\footnotetext{
${ }^{1}$ Images licenced for reuse or reproduced with written consent from patient
} 

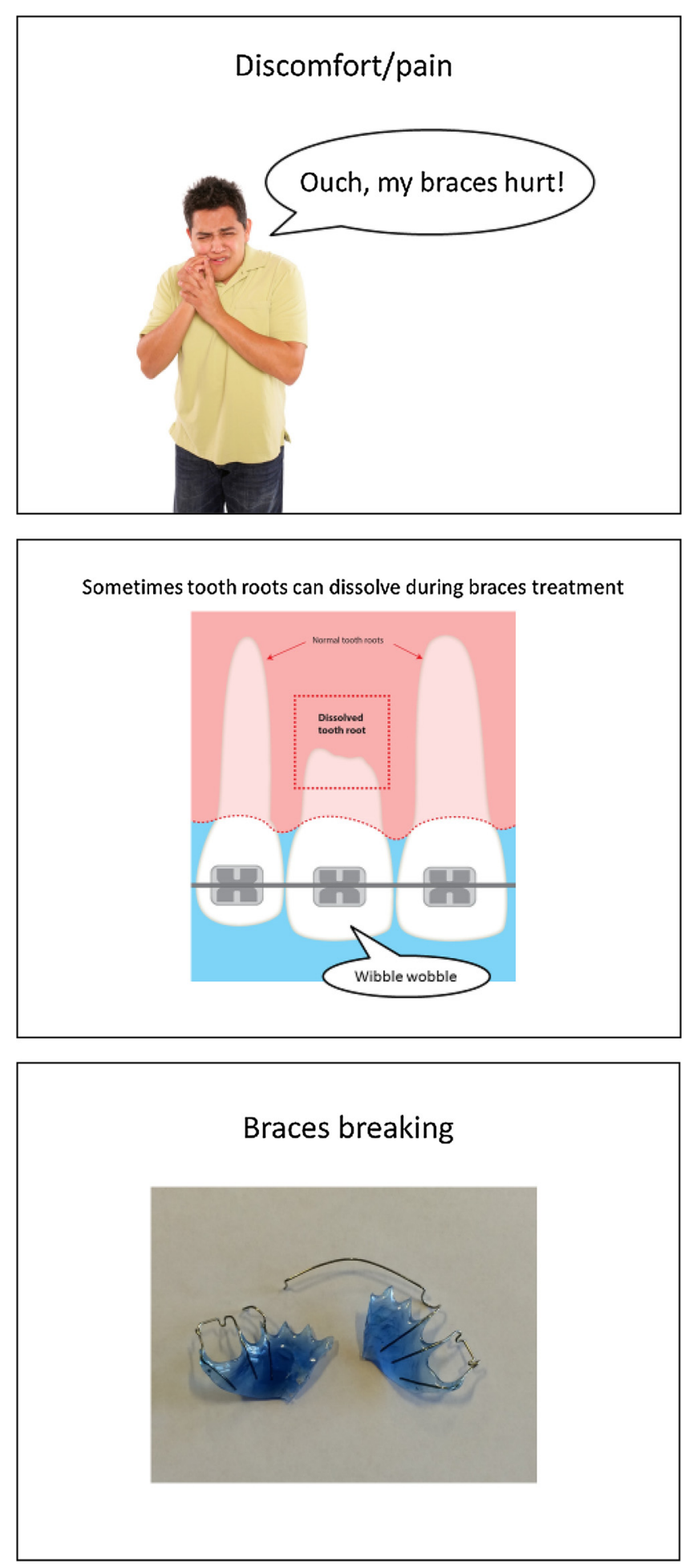


\section{What happens if you don't have braces?}

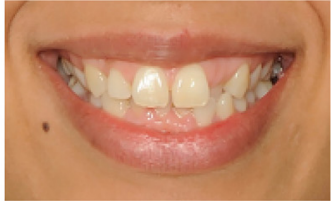

2014

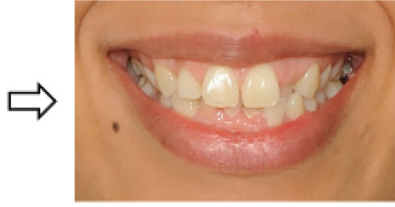

2015

Nothing! If you don't feel you have any problems

\section{After braces are removed the teeth can go crooked again}

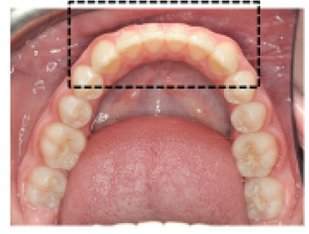

Just after braces removed

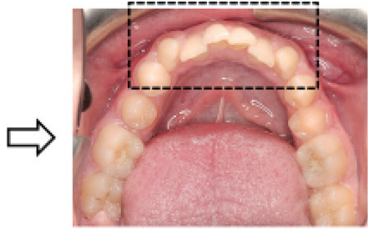

After patient not wearing retainer

\section{References}

[1] Merriam-Webster. 2016. http://www.merriam-webster.com/dictionary/ risk\#medicalDictionary. (Accessed 15 October 2016).

[2] Department of Health, Reference Guide to Consent for Examination or Treatment, (2009).

[3] A. Edwards, G. Naik, H. Ahmed, G.J. Elwyn, T. Pickles, K. Hood, R. Playle, Personalised risk communication for informed decision making about taking screening tests, Cochrane Database Syst. Rev. (2) (2013) CD001865.

[4] K. Asimakopoulou, A. Gupta, S. Scambler, Patient-centred care: barriers and opportunities in the dental surgery, Community Dent. Oral Epidemiol. 42 (6) (2014) 603-610.

[5] N. Apelian, J.N. Vergnes, R. Hovey, C. Bedos, How can we provide person-centred dental care? Br. Dent. J. 223 (6) (2017) 419-424.

[6] P. Ellis, P. Benson, Potential hazards of orthodontic treatment - what your patient should know, Dent. Update 29 (10) (2002) 492-496.

[7] H. Travess, D. Roberts-Harry, J. Sandy, Orthodontics. Part 6: risks in orthodontic treatment, Br. Dent. J. 196 (2) (2004) 71-77.

[8] British Orthodontic Society, Risks of Orthodontic Treatment Member Advice Sheet, (2006).

[9] NHS, Braces and Orthodontics, (2015) http://www.nhs.uk/Livewell/dentalhealth/ Pages/braces.aspx . (Accessed 1 November 2016).

[10] P. McNair, J.R. Gardiner, A.C. Williams Sandy, A qualitative study to develop a tool to examine patients' perceptions of NHS orthodontic treatment, J. Orthod. 33 (2) (2006) 97-106.

[11] R. Hiemstra, A. Bos, J. Hoogstraten, Patients' and parents' expectations of orthodontic treatment, J. Orthod. 36 (4) (2009) 219-228.

[12] R. Wheeler, The new age of consent, Bull. R. Coll. Surg. Engl. 97 (6) (2015) 250-252.

[13] American Association of Orthodontics, Guidelines for Obtaining Informed Consent, (2013).

[14] Canadian Medical Protective Association, Consent: A Guide for Canadian Physicians, (2016).

[15] Rogers v Whitaker, 109 ALR 625-631 [1993] 4 med LR 79-82 (High Court of
Australia), 1992.

[16] R. Stephens, F.S. Ryan, S.J. Cunningham, Information seeking behavior of adolescent orthodontic patients, Am. J. Orthodontics Dentofacial Orthopedics 143 (3) (2012) 303-309.

[17] N. Wright, P.S. Fleming, P.K. Sharma, J. Battagel, Influence of supplemental written information on adolescent anxiety, motivation and compliance in early orthodontic treatment, Angle Orthod. 80 (2) (2010) 329-335.

[18] I.H. Nasr, M. Sayers, T. Newton, Do patient information leaflets affect patients expectation of orthodontic treatment? A randomized controlled trial, J. Orthod. 38 (4) (2011) 257-268.

[19] F. Al-Silwadi, D.S. Gill, A. Petrie, S.J. Cunningham, Effect of social media in improving knowledge among patients having fixed appliance orthodontic treatment: a single-center randomized controlled trial, Am. J. Orthodontics Dentofacial Orthopedics 148 (2) (2015) 231-237.

[20] Z. Marshman, A. Eddaiki, H.L. Bekker, P.E. Benson, Development and evaluation of a patient decision aid for young people and parents considering fixed orthodontic appliances, J. Orthod. 43 (4) (2016) 276-287.

[21] K. Parker, S.J. Cunningham, A. Petrie, F.S. Ryan, Randomized controlled trial of a patient decision-making aid for orthodontics, Am. J. Orthod. Dentofacial Orthop. 152 (2) (2017) 154-160.

[22] O.H. Alkadhi, M.N. Zahid, R.S. Almanea, H.K. Althaqeb, T.H. Alharbi, N.M. Ajwa, The effect of using mobile applications for improving oral hygiene in patients with orthodontic fixed appliances: a randomised controlled trial, J. Orthod. (2017) 1-7.

[23] X. Li, Z.R. Xu, N. Tang, C. Ye, X.L. Zhu, T. Zhou, Z.H. Zhao, Effect of intervention using a messaging app on compliance and duration of treatment in orthodontic patients, Clin. Oral Investig. 20 (8) (2016) 1849-1859.

[24] J.L. Ackerman, W.R. Proffit, Communication in orthodontic treatment planning: bioethical and informed consent issues, Angle Orthod. 65 (4) (1995) 253-261.

[25] M. Habibian, S. Gelbier, B.A. Munday, B.A. Habibian, Perceived information needs in respect of orthodontics amongst 11-12-year-old girls: a study through health visitor sessions in schools, Int. J. Paediatr. Dent. 13 (5) (2003) 348-355.

[26] N.A. Mandall, S. Vine, R. Hulland, H.V. Worthington, The impact of fixed orthodontic appliances on daily life, Community Dent. Health 23 (2) (2006) 69-74.

[27] M. Sayers, J. Newton, Patients' expectations of orthodontic treatment: part 1 development of a questionnaire, J. Orthod. 33 (4) (2006) 258-269 discussion 256. 
[28] F.A. Al Jawad, S.J. Cunningham, N. Croft, A. Johal, A qualitative study of the early effects of fixed orthodontic treatment on dietary intake and behaviour in adolescent patients, Eur. J. Orthod. 34 (4) (2012) 432-436.

[29] L.A. Carter, M. Geldenhuys, P.J. Moynihan, D.R. Slater, C.E. Exley, S.L. Rolland, The impact of orthodontic appliances on eating young peoples views and experiences, J. Orthod. 42 (2) (2015) 114-122.

[30] M.E. Bennett, J.F. Tulloch, Understanding orthodontic treatment satisfaction from the patients' perspective: a qualitative approach, Clin. Orthod. Res. 2 (2) (1999) 53-61.

[31] I. Feldmann, T. List, M. John, L. Bondemark, Reliability of a questionnaire assessing experiences of adolescents in orthodontic treatment, Angle Orthod. 77 (2) (2007) 311-317.

[32] J.W. Pittman, M.E. Bennett, L.D. Koroluk, S.G. Robinson, C.L. Phillips, Characterizing the orthodontic patient's purchase decision: a novel approach using netnography, Am. J. Orthod. Dentofacial Orthop. 151 (6) (2017) 1065-1072.

[33] J. Morse, Determining sample size, Qual. Health Res. 10 (1) (2000) 3-5.

[34] R.A. Krueger, Focus Groups: A Practical Guide for Applied Research, 4th ed., SAGE, Thousand Oaks, CA, London, 2009.

[35] S. Brinkmann, InterViews: Learning the Craft of Qualitative Research Interviewing, 3rd ed., Sage Publications, Los Angeles; London, 2015.

[36] J. Perry, Establishing the Evidence Base for Risk Communication in Orthodontics, Cardiff University, 2018

[37] V. Braun, V. Clarke, Using thematic analysis in psychology, Qual. Res. Psychol. 3 (2) (2006) 77-101.

[38] H.L. Bekker, F. Luther, H. Buchanan, Developments in making patients orthodontic choices better, J. Orthod. 37 (3) (2010) 217-224.

[39] J.L. McComb, J.F. Wright, N.A. Fox, K.D. O'Brien, Perceptions of the risks and benefits of orthodontic treatment, Community Dent. Health 13 (3) (1996) 133-138.

[40] M.E. Bennett, C. Michaels, K. O'Brien, R. Weyant, C. Phillips, K. Dryland, Measuring beliefs about orthodontic treatment: a questionnaire approach, J. Public Health Dent. 57 (4) (1997) 215-223.

[41] A. Benthin, et al., A psychometric study of adolescent risk perception, J. Adolesc. 16 (2) (1993) 153-168.

[42] K. Asimakopoulou, J.T. Newton, B. Daly, Y. Kutzer, M. Ide, The effects of providing periodontal disease risk information on psychological outcomes - a randomized controlled trial, J. Clin. Periodontol. 42 (4) (2015) 350-355.

[43] A. Tversky, D. Kahneman, Judgment under uncertainty: heuristics and biases, Science (New York, N.Y.) 185 (4157) (1974) 1124-1131.

[44] P. Slovic, B. Fischhoff, S. Lichtenstein, Behavioral decision theory perspectives on risk and safety, Acta Psychol. 56 (1-3) (1984) 183-203.

[45] P. Slovic, The Perception of Risk, Earthscan Publications, London and Sterling, VA, 2000.

[46] J. Nurmi, How do adolescents see their future? A review of the development of future orientation and planning, Dev. Rev. 11 (1) (1991) 1-59.

[47] J.F. Baird, H. Kiyak, The uninformed orthodontic patient and parent: treatment outcomes, Am. J. Orthodontics Dentofacial Orthopedics 124 (2) (2003) 212-215.

[48] M.G. Mortensen, H. Kiyak, L. Omnell, Patient and parent understanding of informed consent in orthodontics, Am. J. Orthodontics Dentofacial Orthopedics 124 (5) (2003) 541-550.

[49] Dental Protection Limited, The Dento-Legal Aspects of Orthodontics, (2016).

[50] I. Mills, J. Frost, D. Moles, E. Kay, Patient- centred care in general dental practice: sound sense or soundbite? Br. Dent. J. 215 (2) (2013) 81-85.

[51] F. Ryan, S. Cunningham, Shared decision making in healthcare, Faculty Dent. J. 5 (3) (2014) 124-127.

[52] J. Kitzinger, Qualitative research. Introducing focus groups, Br. Med. J. 311 (7000) (1995) 299-302.

[53] P. Gill, K. Stewart, E. Treasure, B. Chadwick, Methods of data collection in qualitative research: interviews and focus groups, Br. Dent. J. 204 (6) (2008) 291-295. 